\title{
Preparation of Bisphenol-A and Polydimethylsiloxane (PDMS) Block Copolycarbonates by Melt Polycondensation: Effects of PDMS Chain Length on Conversion and Miscibility
}

\author{
Zibo Zhou and Guozhang $\mathrm{Wu}$ * \\ Shanghai Key Laboratory of Advanced Polymeric Materials, School of Materials Science \& Engineering, \\ East China University of Science \& Technology, Shanghai 200237, China; s13867700926@163.com \\ * Correspondence: wgz@ecust.edu.cn
}

check for updates

Citation: Zhou, Z.; Wu, G Preparation of Bisphenol-A and Polydimethylsiloxane (PDMS) Block Copolycarbonates by Melt

Polycondensation: Effects of PDMS Chain Length on Conversion and Miscibility. Polymers 2021, 13, 2660. https://doi.org/10.3390/polym 13162660

Academic Editors: Edina Rusen and Agnieszka Tercjak

Received: 18 July 2021

Accepted: 3 August 2021

Published: 10 August 2021

Publisher's Note: MDPI stays neutral with regard to jurisdictional claims in published maps and institutional affiliations.

Copyright: (C) 2021 by the authors Licensee MDPI, Basel, Switzerland. This article is an open access article distributed under the terms and conditions of the Creative Commons Attribution (CC BY) license (https:/ / creativecommons.org/licenses/by/ $4.0 /)$.

\begin{abstract}
This study aimed to improve polydimethylsiloxane (PDMS) conversion in the preparation of polycarbonate (PC)-polydimethylsiloxane (PDMS) copolymer through melt polycondensation. We examined the transesterification process of PDMS with diphenyl carbonate (DPC) and its copolymerization products with bisphenol-A (BPA) for different chain lengths of PDMS. The key factors affecting PDMS conversion were investigated. Results showed that long-chain PDMS required a higher critical transesterification level (38.6\%) to improve miscibility with DPC. During polycondensation, side reactions were more prone to occur when the equilibrium transesterification level of long-chain PDMS was lower. PDMS conversion was also lower when more short-chain PDMS was fed. Increasing the chain length of PDMS also reduced PDMS conversion. Notably, increasing the amount of $\mathrm{KOH}$ can significantly improve PDMS conversion throughout the polycondensation stage by increasing the equilibrium transesterification level of long-chain PDMS, thereby inhibiting the occurrence of side reactions.
\end{abstract}

Keywords: PC-PDMS copolymer; melt polycondensation; miscibility; equilibrium transesterification level; conversion

\section{Introduction}

Polycarbonate (PC) is widely applied in various fields such as electronics, automotive parts, constructions, and medical equipment due to its excellent optical and mechanical properties, including transparency and impact strength [1-3]. However, its utilization still faces challenges because new designs tend to emphasize more on key application areas requiring thin-wall parts, complex geometries, and high-impact products that can withstand very low temperatures with no compromise on flow and processability. Meanwhile, PC shows a V-2 rating in the UL-94 test, meaning it does not meet fire-safety requirements. For this reason, PC modification with other components through copolymerization and melt blending has been extensively studied over the last four decades [4-6].

Polydimethylsiloxane (PDMS) molecules have relatively flexible polymer backbones (or chains) with a low glass-transition temperature, resulting in low temperature ductility, high thermal stability, and versatile functionality. Thus, PDMS is an ideal flame retardant or impact modifier for PC. These disadvantages can be compensated for through copolymerization with PDMS, which generally shows higher polymer-chain flexibility $[7,8]$. The introduction of PDMS into the PC main chain enables an easy process of PC and improves its low-temperature toughness, weatherability, hydrolytic stability, and flame retardancy [9-15]. Compared with traditional interfacial phosgenation, melt-condensation polymerization is a green process not requiring the use of hazardous phosgene and chlorinated solvent. Thus, this efficient and friendly method can be applied in preparing PC-PDMS copolymer for industrial production.

The preparation of PC-PDMS copolymers by melt polycondensation is greatly hindered by the difficulty of increasing PDMS conversion. PDMS and DPC are immiscible with 
each other due to the large difference in their solubility parameters $\left(\delta_{\mathrm{DPC}}=10.53 \mathrm{cal}^{1 / 2} \mathrm{~cm}^{-3 / 2}\right.$ vs. $\left.\delta_{\mathrm{PDMS}}=7.3 \mathrm{cal}^{1 / 2} \mathrm{~cm}^{-3 / 2}\right)[16,17]$. Thus, PDMS cannot be well-dispersed in DPC or PC oligomers in the melt state, thereby suppressing the transesterification reaction of PDMS to some extent [18]. King et al. [19] demonstrated that hydroxyl-terminated PDMS with long chains cannot achieve high conversion through melt polycondensation (only 3-5\%), as experimentally observed by Koenig et al. [20] Moreover, the immiscibility between PC and PDMS is a key factor affecting the heat resistance, impact resistance, and optical transparency of PC-PDMS copolymers. Zhang et al. [21] and Zhou et al. [22] reported that PC-PDMS copolymer formed in situ in PC/PDMS blend under the action of transesterification catalyst helps improve the miscibility between the two. Therefore, we consider that PDMS and DPC should be reacted first in the transesterification stage. Afterwards, the end group of PDMS changes, which is beneficial to improving the miscibility with DPC or PC oligomers, and then it reacts with BPA or PC oligomers to obtain the desired products. Thus, the change in miscibility influences PDMS conversion during transesterification.

A series of siloxane equilibrium reactions occur during transesterification under the action of strong bases, including the linear condensation between PDMS and PDMS or the cyclic degradation of PDMS itself, thereby affecting the transesterification ratios of PDMS [23]. The former increases the average chain length of PDMS, and the latter decreases its average chain length. Either raising temperature or lowering pressure can break the equilibrium state and affect the form of PDMS in the melt. GE and Bayer have found that the siloxane chain is severely decomposed by siloxane-chain scission followed by siloxane depolymerization to give cyclic siloxanes during the typical melt process [24,25]. Cyclic siloxanes formed in this process remain in the polymer and have an exceptionally disruptive effect on applications in the electrical/electronic sector [26-28]. Another potential problem regarding PC-PDMS copolymer synthesis, which is relatively neglected often, is the stability of the hydroxyl end groups in PDMS oligomers. Hydroxyl-end groups can backbite the terminal silicon atoms in PDMS oligomers, leading to the formation of cyclic siloxane and the loss of end-group functionality, thereby inhibiting the introduction of PDMS into the PC chain. To improve PDMS conversion, the equilibrium conversion rate of PDMS in the transesterification stage must be increased to promote the miscibility of PDMS with PC oligomers while reducing the residual amount of PDMS and inhibiting the occurrence of side reactions.

Accordingly, the present study initially examined the transesterification process between PDMS and DPC and investigated the degree of transesterification reaction required for different chain lengths of PDMS and DPC to reach a critical miscibility state, as well as the final equilibrium transesterification level. The effects of the feed amount of PDMS and the average chain length on PDMS conversion during melt polycondensation were then investigated. We found that PDMS conversion in the final product depended on the equilibrium conversion rate at the transesterification stage. Finally, a solution strategy was provided to effectively increase PDMS conversion.

\section{Materials and Methods}

\subsection{Materials}

Bisphenol-A (BPA; 99.0\%), diphenyl carbonate (DPC; 99.0\%), and potassium hydroxide (KOH; $95 \%)$ were provided by Aladdin. Anhydrous alcohol $\left(\mathrm{CH}_{3} \mathrm{CH}_{2} \mathrm{OH} ; 99.7 \%\right)$, dichloromethane $\left(\mathrm{CH}_{2} \mathrm{Cl}_{2} ; 99.5 \%\right)$, chloroform $\left(\mathrm{CHCl}_{3} ; 99.0 \%\right)$, and n-hexane $\left(\mathrm{C}_{6} \mathrm{H}_{14} ; 97 \%\right)$ were purchased from Shanghai Titan. DPC was purified by recrystallization in anhydrous ethanol three times.

Silanol-terminated PDMS with an average chain length of 5.3 and 22.5 was supplied by Shenzhen Ji-Peng Silicone Fluoride Materials Co. (Shenzhen, China) and denoted as Silanol $_{5.3}$ and Silanol 22.5 , respectively. Another silanol-terminated PDMS with an average chain length of 56.2, denoted as Silanol 56.2 , was provided by ThermoFisher Scientific (Shanghai, China). The average chain length of PDMS was determined by ${ }^{1} \mathrm{H}-\mathrm{NMR}$ as described below. The chemical structures of BPA, PDMS, and DPC are shown in Figure 1. 
<smiles>CC(C)(c1ccc(O)cc1)c1ccc(O)cc1</smiles>

(a)<smiles>CC(C)(O)O[Si](C)(C)C(C)(C)O</smiles>

(b)<smiles>O=C(Oc1ccccc1)Oc1ccccc1</smiles>

(c)

Figure 1. Chemical structures of (a) BPA, (b) PDMS, and (c) DPC.

\subsection{Melt-Transesterification Reaction of DPC and PDMS}

Equimolar amounts of DPC and PDMS with different average chain lengths were poured into a $100 \mathrm{~mL}$ four-neck round-bottom glass flask fitted with a reflux condenser. The flask was evacuated and refilled with dry nitrogen gas three times and then heated in a $180{ }^{\circ} \mathrm{C}$ silicone oil bath. The addition of $\mathrm{KOH}(0.01 \mathrm{~mol} \%$ vs. PDMS $)$ into the melted mixture was considered the start of the reaction, and a small amount of sample was extracted from the reactor at set intervals. Each sample was sealed and stored in a refrigerator for analysis and direct characterization by nuclear magnetic resonance (NMR) and optical microscopy $(\mathrm{OM})$.

\subsection{Synthesis of BPA/PDMS Copolycarbonates}

Different amounts of Silanol 5.3 were introduced into BPA and DPC mixtures. The molar ratio of DPC/BPA was set at 1.06, and the BPA/PDMS molar ratio was changed to $100 / 0,99 / 1,98 / 2,96 / 4,94 / 6,92 / 8$, and 90/10. The total amount of monomer was $77 \mathrm{mmol}$. A KOH amount of $100 \mathrm{ppm}$ to diols on a mole basis was used. Whole reactants were placed in a $100 \mathrm{~mL}$ three-neck round-bottom flask equipped with a mechanical stirrer and high-vacuum bearing. The temperature was increased to $180{ }^{\circ} \mathrm{C}$ with mechanical stirring under $\mathrm{N}_{2}$ atmosphere. The material was allowed to melt for $10 \mathrm{~min}$, and then the temperature was kept constant for $15 \mathrm{~min}$ to make the transesterification reach equilibrium. Then, the temperature was increased to $210{ }^{\circ} \mathrm{C}$, and the pressure was gradually reduced to $120 \mathrm{mmHg}$. The temperature was held for $45 \mathrm{~min}$ to distill off phenol. Subsequently, the temperature was raised to $270{ }^{\circ} \mathrm{C}$ over the next $15 \mathrm{~min}$, after which the pressure was reduced to $30 \mathrm{mmHg}$. After further reaction for $10 \mathrm{~min}$, the final temperature was set at $280^{\circ} \mathrm{C}$, and the pressure was reduced to less than $1 \mathrm{mmHg}$. This condition was maintained for $10 \mathrm{~min}$ to complete the reaction. The synthesized polymer was cooled to room temperature, dissolved in dichloromethane, and precipitated in an appropriate amount of $\mathrm{n}$-hexane accompanied by ultrasonic cleaning for $1 \mathrm{~h}$ to remove unreacted PDMS. The final product was collected by vacuum filtration and dried in a vacuum oven at $100{ }^{\circ} \mathrm{C}$ for $24 \mathrm{~h}$ until their use for characterizations.

A similar procedure was performed using Silanol $_{22.5}$ and Silanol $_{56.2}$ as raw materials. The molar ratio of DPC to BPA was kept at 1.06, and the amount of PDMS was set at $6 \mathrm{~mol} \%$ BPA.

\subsection{Characterizations}

ATR-FTIR experiments were performed on a Nicolet 5700 spectrometer with a DTGS detector in the range of $400-4000 \mathrm{~cm}^{-1}$ at a resolution of $4 \mathrm{~cm}^{-1}$. The samples were dissolved in dichloromethane at a concentration of $5 \mathrm{wt} \%$, and then $50 \mu \mathrm{L}$ of solution was spread on a $\mathrm{KBr}$ pellet. The solvent was removed by vacuum desiccation at room temperature before ATR-FTIR analysis.

${ }^{1} \mathrm{H},{ }^{13} \mathrm{C}$, and ${ }^{29} \mathrm{Si}$ NMR spectroscopic measurements were conducted using a Bruker DMX-600 NMR spectrometer. $\mathrm{CDCl}_{3}$ with TMS served as deuterium solvents. The incorporated ratios, block contents, and conversions of PDMS were designated as $N_{\text {PDMS }}, W_{\text {PDMS }}$, and Conversion, respectively. They were measured by

$$
N_{\text {PDMS }}=\frac{\frac{[a]}{6 \times n_{\text {PDMS }}}}{\frac{[a]}{6 \times n_{\text {PDMS }}}+\frac{[b]}{6}}
$$




$$
\begin{gathered}
W_{\mathrm{PDMS}}=\frac{74.1 \times[a]}{74.1 \times[a]+254 \times[b]} \times 100 \% \\
\text { Conversion }(\%)=\frac{N_{\mathrm{PDMS}}}{N_{0}}
\end{gathered}
$$

where $[a]$ represents an integrated value of a methyl group in a dimethylsiloxane moiety observed at around $\delta-0.06$ to $0.3,[b]$ represents an integrated value of a methyl group in a BPA moiety observed at around $\delta 1.5$ to 1.9 , and $N_{0}$ represents the initial feed amount of PDMS.

The molecular weights and molecular-weight distributions of silanols were determined by gel permeation chromatography (GPC). The measurements were performed using a Waters 1515 HPLC pump equipped with a refractive-index detector (Waters 2414). Tetrahydrofuran (THF) was used as the mobile phase at a flow rate of $1 \mathrm{~mL} / \mathrm{min}$ at $35^{\circ} \mathrm{C}$. Weight-average molecular weight $\left(M_{\mathrm{w}}\right)$ and polydispersity index (PDI) were determined against linear polystyrene standards.

The viscosity-average molecular weight $\left(M_{\eta}\right)$ of the polycondensation product was determined with an Ubbelohde viscometer at $25 \pm 0.5^{\circ} \mathrm{C}$ using $\mathrm{CHCl}_{3}$ as the solvent and was calculated by Equations (4) and (5) as follows [29]:

$$
\begin{gathered}
{[\eta]=\sqrt{2\left(\eta_{\mathrm{sp}}-\ln \eta_{\mathrm{r}}\right)} / C} \\
{[\eta]=K M_{\eta}^{\alpha}}
\end{gathered}
$$

where $C$ is the concentration of the solution (always $0.01 \mathrm{~g} \mathrm{~mL}^{-1}$ ), $\eta_{\mathrm{r}}$ is the relative viscosity, and $\eta_{\mathrm{sp}}$ is the specific viscosity. According to ref. [29], the characteristic parameters $K$ and $\alpha$ of BPA-PC are $0.0111 \mathrm{~mL} \mathrm{~g}^{-1}$ and 0.82 , respectively.

Similarly, the $M_{\eta}$ of PDMS can also be determined using an Ubbelohde viscometer. When $\mathrm{CHCl}_{3}$ was replaced with toluene as the solvent, it can be described as follows:

$$
[\eta]=2 \times 10^{-2} M_{\eta}^{0.66}
$$

Color difference $(\Delta C)$, which represents the yellowness of the synthesized product, was measured with an ultraviolet spectrophotometer (UV-vis; UV1900, Youke Instrument). A $\mathrm{CHCl}_{3}$ solution with a concentration of $0.01 \mathrm{~g} \mathrm{~mL}^{-1}$ was used, and $\Delta C$ was determined by:

$$
\Delta C=\left(\left|\frac{1}{3}-\frac{T_{445}}{T}\right|+\left|\frac{1}{3}-\frac{T_{555}}{T}\right|+\left|\frac{1}{3}-\frac{T_{600}}{T}\right|\right) \times 100 \%
$$

where $T_{445}, T_{555}$, and $T_{600}$ represent the transmittance of the solution relative to $\mathrm{CHCl}_{3}$ at wavelengths of 445,555 , and $600 \mathrm{~nm}$. Furthermore, $T=T_{445}+T_{555}+T_{600}$.

The morphology of transesterification products was observed using an OM system (Olympus CX21). We took a drop of transesterification product onto a glass slide, gently pressed the sample to flow naturally, and used a low-power zoom lens $(40 \times 10)$ to observe the changes in the morphology of the two phases.

The glass-transition temperature $\left(T_{\mathrm{g}}\right)$ of PC was measured with a differential scanning calorimetry (DSC) system (DSC25, TA Instruments) within $20^{\circ} \mathrm{C}$ to $250{ }^{\circ} \mathrm{C}$ at a heating rate of $10{ }^{\circ} \mathrm{C} \mathrm{min}^{-1}$ in $\mathrm{N}_{2}$ atmosphere. To eliminate the thermal history of the samples, $T_{\mathrm{g}}$ was determined as the inflection point of the transition during the second heating process.

The decomposition temperature was tested using a thermogravimetric analysis (TGA) apparatus (Netzsch STA 409). The samples were heated from $50{ }^{\circ} \mathrm{C}$ to $800{ }^{\circ} \mathrm{C}$ at a heating rate of $10{ }^{\circ} \mathrm{C} \mathrm{min}^{-1}$ under a nitrogen flow of $50 \mathrm{~mL} \mathrm{~min}^{-1}$. The $5 \%$ weight-loss temperature was recoded as $T_{d, 5 \%}$. 


\section{Results and Discussions}

\subsection{Molecular Structures of Silanol-Terminated PDMS}

Figure 2 shows the ATR-IR spectra of PDMS with different chain lengths. A broad absorption peak appeared at $3000-3700 \mathrm{~cm}^{-1}$ due to the stretching vibration of the terminal hydroxyl group. The average chain length of Silanol $_{5.3}$ was shorter with a higher hydroxyl content, resulting in a broader absorption peak. Meanwhile, shorter-chain PDMS oligomers were more likely to form hydrogen bonds between the chains, leading to a redshift of the absorption peak [30].

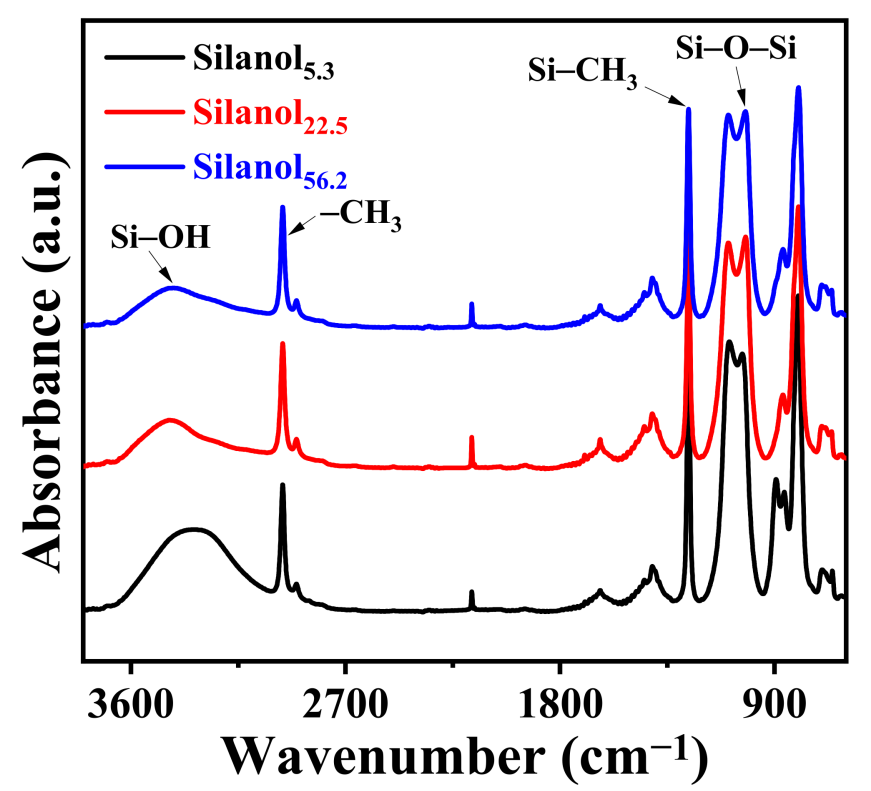

Figure 2. ATR-IR spectra of silanol-terminated PDMS with different block lengths.

Figure 3 shows the GPC curves of PDMS with different chain lengths. From the graph, the molecular weights and molecular-weight distributions of Silanols can be analyzed. We observed that PS standard and PDMS with different chain lengths peaked at $33 \mathrm{~min}$, indicating that this peak was not the main peak of PDMS. The GPC data of the main peak of PDMS with different chain lengths are given in Table 1. Silanol ${ }_{56.2}$ and Silanol $_{22.5}$ with longer chain lengths had wider molecular-weight distribution and a more complex structure than Silanol $1_{5.3}$.

Table 1. Basic information of silanol-terminated PDMS with different chain lengths.

\begin{tabular}{|c|c|c|c|c|c|c|c|}
\hline Sample ID & Viscosity (cP) & $M_{\eta}{ }^{1}(\mathrm{~g} / \mathrm{mol})$ & $M_{\mathrm{w}}^{2}(\mathrm{~g} / \mathrm{mol})$ & $\mathrm{PDI}^{2}$ & $W_{\text {theo. }}{ }^{3}$ & $W_{\text {cal. }}{ }^{4}$ & $n_{\text {PDMS }}{ }^{5}$ \\
\hline Silanol $_{5.3}$ & 30 & 1700 & 2200 & 1.12 & 8.0 & 8.3 & 5.3 \\
\hline Silanol $_{22.5}$ & 60 & 2200 & 2630 & 1.21 & 4.0 & 4.1 & 22.5 \\
\hline Silanol $_{56.2}$ & 100 & 4900 & 5200 & 1.23 & 0.8 & 0.8 & 56.2 \\
\hline
\end{tabular}

${ }^{1}$ Calculated with Equation (6); ${ }^{2}$ determined by THF-GPC using polystyrene standards (RI detector); ${ }^{3}$ theoretical hydroxyl group content of Silanols $\left(W_{\text {theo. }}\right) ;{ }^{4}$ calculated hydroxyl group content of Silanols $\left(W_{\text {cal. }}\right)$ measured by ${ }^{1} \mathrm{H}-\mathrm{NMR}$ analysis; ${ }^{5}$ calculated by the $W_{\text {cal. }}$ obtained from ${ }^{1} \mathrm{H}$-NMR.

Figure 4 shows the ${ }^{1} \mathrm{H}-\mathrm{NMR}$ spectra of PDMS with different average chain lengths. The peaks at $\delta 2.13$ and $2.14 \mathrm{ppm}$ were assigned to the hydrogen atom of terminal hydroxyl groups of Silanol $_{22.5}$ and Silanol 56.2 , respectively. The shorter-chain PDMS had a higher content of hydroxyl groups, which were easily induced by the hydrogen bonding of the terminal hydroxyl group of neighboring molecular chains and moved toward a lower field at $\delta 3.20 \mathrm{ppm}$, where the peak widened. The relative values of the absorption peak area of $\mathrm{Si}-\mathrm{CH}_{3}$ near $0 \mathrm{ppm}$ on the main chain and $\mathrm{Si}-\mathrm{OH}$ enabled the calculation of the terminal 
hydroxyl content of PDMS with different average chain lengths. The average chain length of PDMS obtained was similar to the theoretical chain length.

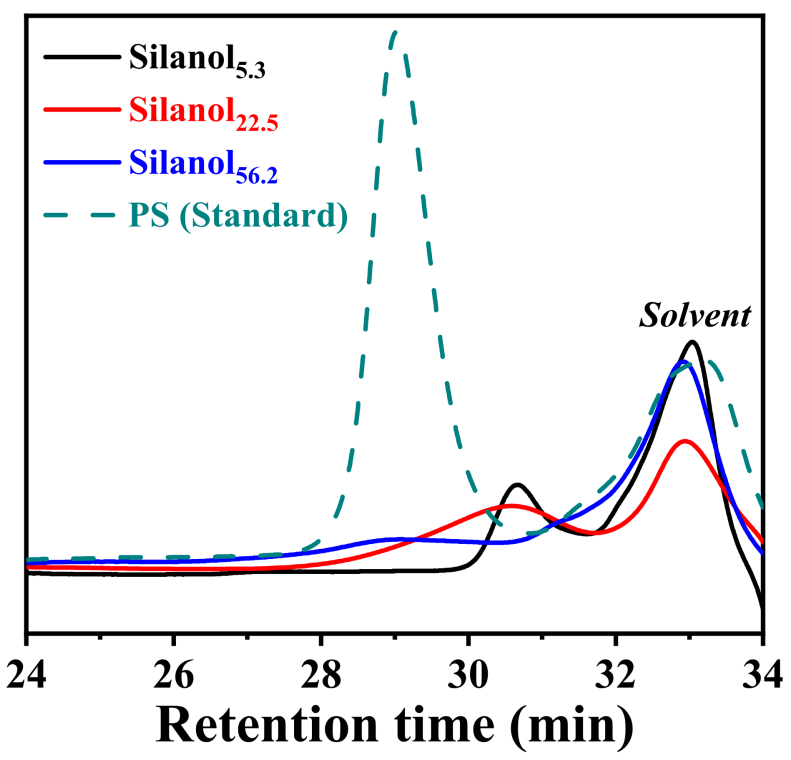

Figure 3. GPC curves of silanol-terminated PDMS with different chain lengths.

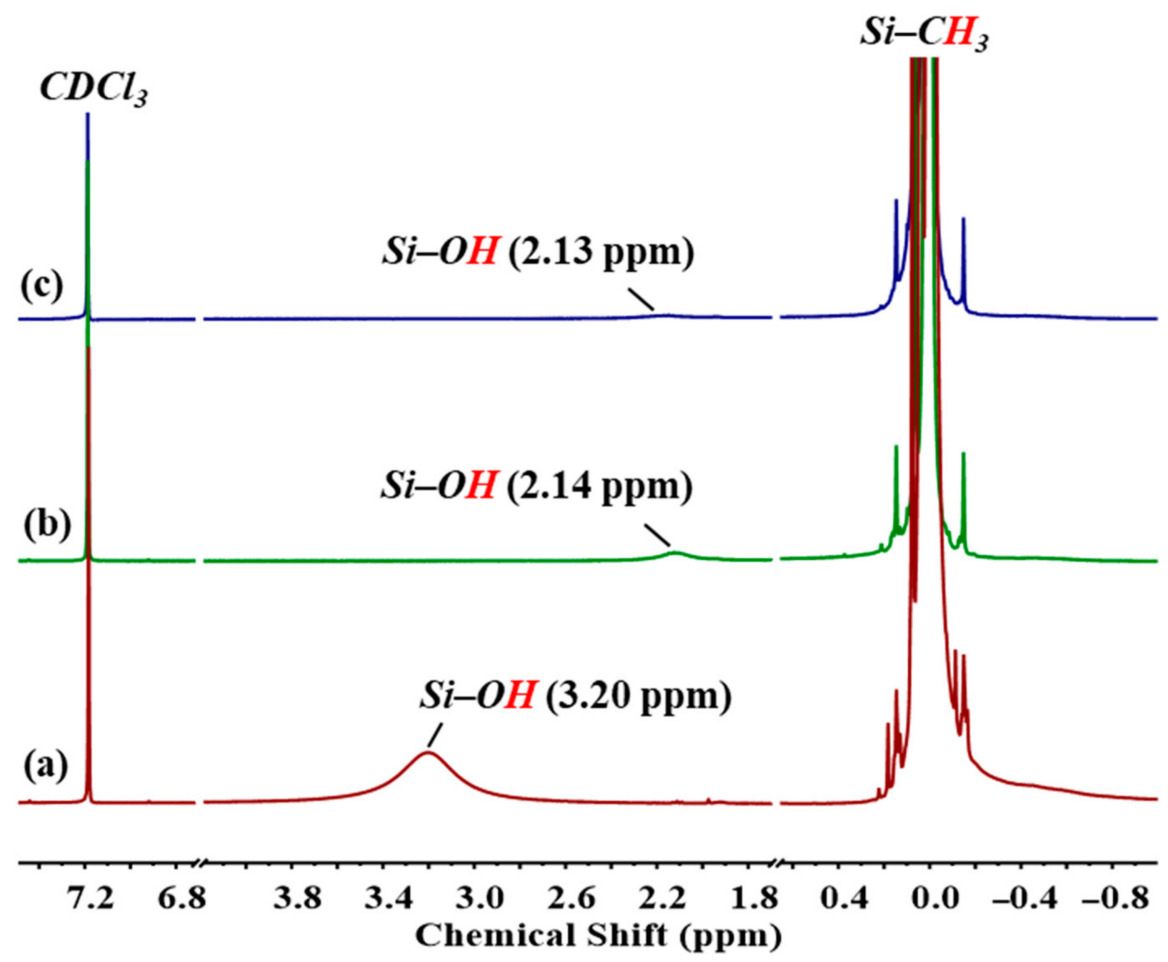

Figure 4. ${ }^{1} \mathrm{H}-\mathrm{NMR}$ spectra of (a) Silanol $_{5.3}$, (b) Silanol $_{22.5}$, and (c) Silanol 56.2 .

\subsection{Melt-Transesterification Process of DPC and PDMS}

Differences may exist in the miscibility of DPC and PDMS with different average chain lengths during the melt-transesterification stage, which may affect the equilibrium transesterification conversion of PDMS. For this reason, we reacted PDMS having different chain lengths with DPC catalyzed by $\mathrm{KOH}$. Samples were extracted from the reactor at set intervals for analyses through ${ }^{1} \mathrm{H}-\mathrm{NMR}$ and $\mathrm{OM}$ to verify whether the miscibility of the mixture was improved by the transesterification between PDMS and DPC. 
Figure 5 gives the OM photographs of transesterification products obtained from DPC and PDMS with different chain lengths reacted at different times. Transesterification temperature was set at $180^{\circ} \mathrm{C}$, and the molar ratio of DPC to PDMS was controlled at 1:1. Figure 5 shows that when the chain length of PDMS was shorter, more DPC was added and more DPC crystals appeared on the OM photographs. However, the results in Figure 5 revealed that the experiments of Silanol ${ }_{5.3}$ had fewer DPC crystals before $\mathrm{KOH}$ addition than the other two Silanols with larger average chain lengths. The ${ }^{1} \mathrm{H}-\mathrm{NMR}$ spectra of the transesterification products of DPC and PDMS with different average chain lengths before $\mathrm{KOH}$ addition are shown in Figure 6. Silanol ${ }_{5.3}$ had already undergone transesterification with DPC, and at this point, $1.8 \%$ DPC conversion had been achieved. By the time the reaction reached $3 \mathrm{~min}, 5.2 \%$ DPC was consumed, and the relatively small volume of Silanol $_{5.3}$ more easily dissolved in the remaining DPC due to the change in end group, reflected in the OM photographs as the complete disappearance of DPC crystals. The DPC consumption deduced from ${ }^{1} \mathrm{H}-\mathrm{NMR}$ at this moment can be regarded as the critical transesterification level when DPC and PDMS reached mutual miscibility.


Figure 5. OM photographs of transesterification products of DPC/Silanol ${ }_{5.3}$ reacted for (a) $0 \mathrm{~min}$, (b) $3 \mathrm{~min}$ and (c) $6 \mathrm{~min}, \mathrm{DPC} / \mathrm{Silanol}_{22.5}$ reacted for (d) $0 \mathrm{~min}$, (e) $3 \mathrm{~min}$ and (f) $6 \mathrm{~min}$ and DPC/Silanol 56.2 reacted for (g) $0 \mathrm{~min},(\mathbf{h}) 3 \mathrm{~min}$ and (i) $9 \mathrm{~min}$ at $180^{\circ} \mathrm{C}$.

Table 2 shows the critical transesterification level of DPC and PDMS with different average chain lengths to reach mutual miscibility. With an increased average chain length of PDMS, the critical transesterification level for the complete disappearance of DPC crystals also increased. A conversion rate of $17.0 \%$ for DPC was required with Silanol 22.5 and $38.6 \%$ for DPC with Silanol 56.2 for PDMS to be completely dissolved in DPC. This phenomenon indicated that PDMS with a longer average chain length required a higher critical transesterification level to be soluble in the melt with DPC, also indicating that PDMS with different chain lengths had certain solubility differences. 


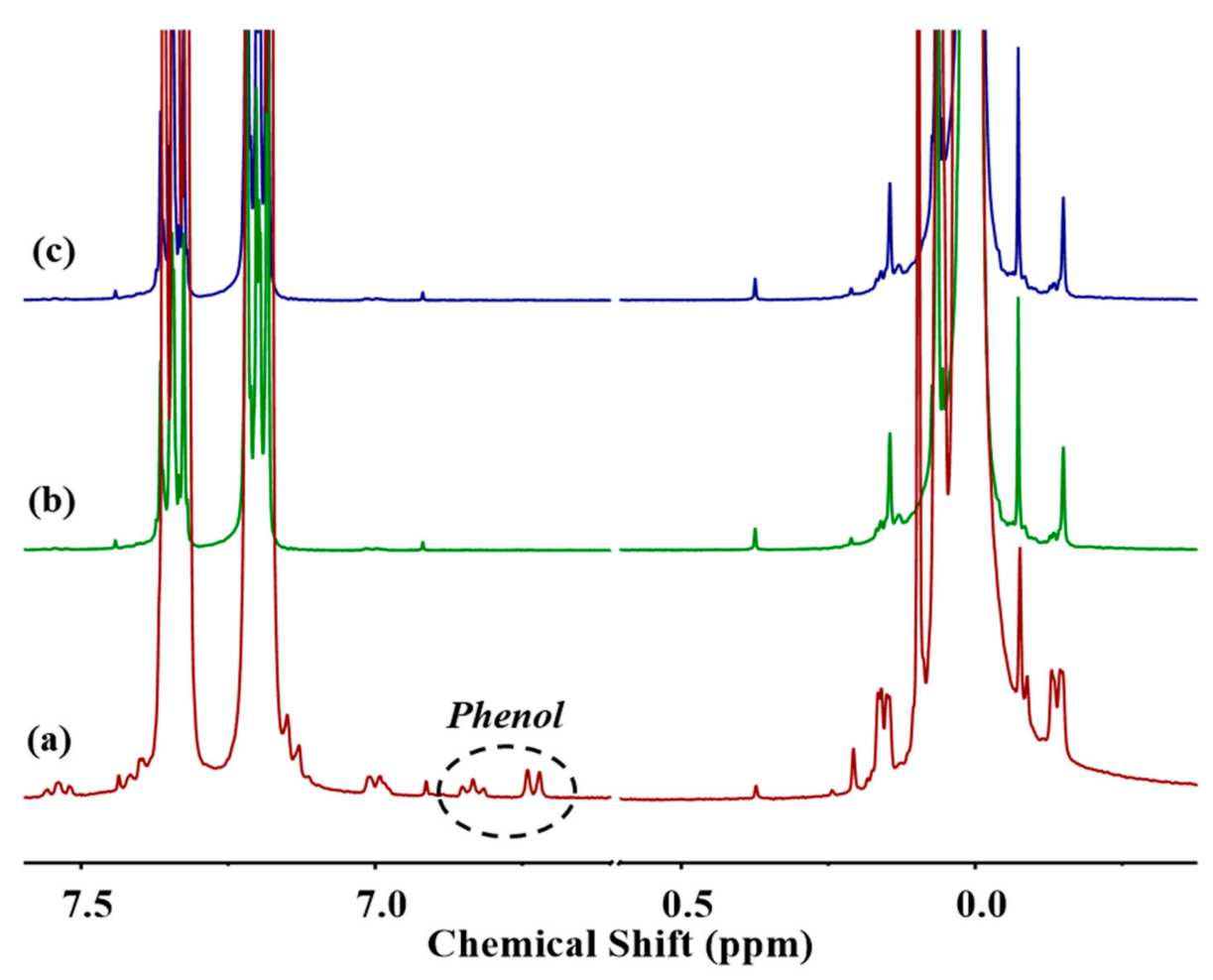

Figure 6. ${ }^{1} \mathrm{H}-\mathrm{NMR}$ spectra of first transesterification product of (a) Silanol $_{5.3}$, (b) Silanol $_{22.5}$, and (c) Silanol $_{56.2}$ reacted with DPC under the action of $100 \mathrm{ppm} \mathrm{KOH}$ at $180{ }^{\circ} \mathrm{C}$.

Table 2. Critical transesterification level of silanol-terminated PDMS with different chain lengths reacted with DPC to reach two-phase intermiscibility.

\begin{tabular}{cc}
\hline Sample ID & Critical Transesterification Level (\%) \\
\hline Silanol $_{5.3}$ & 5.3 \\
Silanol $_{22.5}$ & 17.0 \\
Silanol $_{56.2}$ & 38.6 \\
\hline
\end{tabular}

Figure 7 presents the change curve of the transesterification level of DPC and PDMS with different chain lengths over time. It should be pointed out that under the catalysis of high concentrations of $\mathrm{KOH}$, prolonging the reaction time may cause side effects such as thermal degradation or rearrangement of PDMS, which affect the calculation of the transesterification level. Therefore, we determined a suitable duration of $100 \mathrm{~min}$ for the transesterification. Transesterification between Silanol 56.2 and DPC already reached equilibrium by $100 \mathrm{~min}$, and the conversion of DPC was constant at $38.6 \%$. Conversely, the two sets of experiments on Silanol ${ }_{5.3}$ and Silanol $_{22.5}$ did not yet reach equilibrium, and the transesterification levels of the end product were $51.5 \%$ and $45.6 \%$, respectively. This finding explained why long-chain PDMS was more difficult to introduce into the PC backbone, affecting its conversion in the melt-polycondensation process for the preparation of PC-PDMS copolymers.

Figure 8 reveals the ${ }^{29} \mathrm{Si}-\mathrm{NMR}$ spectra of pristine PDMS with different chain lengths and their transesterification products with DPC. Figure 8 shows that a new peak appeared at around $\delta-13.72 \mathrm{ppm}(\alpha)$, which was believed to originate from DPC-PDMS oligomers formed by transesterification. Moreover, according to the literature, some cyclic siloxanes may be present during the preparation of silanols, and the main structures would be $\mathrm{D}_{3}, \mathrm{D}_{4}, \mathrm{D}_{5}$, and $\mathrm{D}_{6}$, showing peaks at $-9.2,-20,-22.6$, and $-23.0 \mathrm{ppm}$ in that order [31,32]. Figure 8 shows that PDMS with different chain lengths did not display any peak at the above positions, and no cyclic siloxanes formed in the final transesterification products after reacting with DPC at $180^{\circ} \mathrm{C}$ for $100 \mathrm{~min}$. This finding meant that PDMS itself did not suffer 
from side reactions such as cyclic degradation during the melt-transesterification stage within $100 \mathrm{~min}$. However, the unconverted long-chain PDMS during transesterification may be more susceptible to side reactions at high temperatures and strong bases, reducing PDMS conversion. The experimental results confirmed that improving PDMS conversion in melt polycondensation and suppressing possible side reactions required the selection of PDMS with lower viscosity, shorter chain length, and higher activity as the raw material. This selection would ensure the enhancement in PDMS conversion in the transesterification stage and the elimination of the effect of terminal reactive groups on the side reactions, such as chain tailoring or self-condensation.

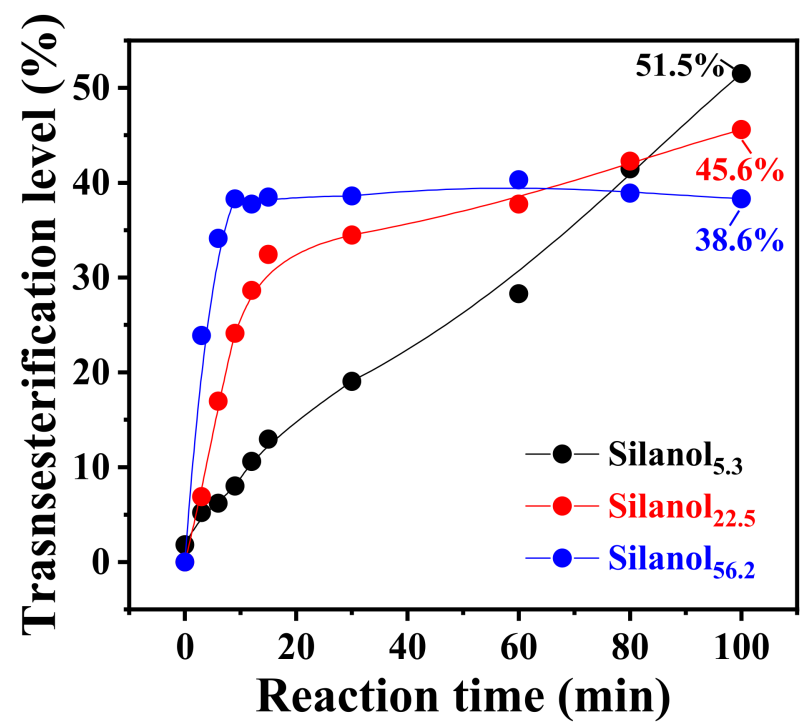

Figure 7. Time dependence of transesterification level of silanols with different average chain lengths reacted with DPC catalyzed by $\mathrm{KOH}$ at $180^{\circ} \mathrm{C}$.

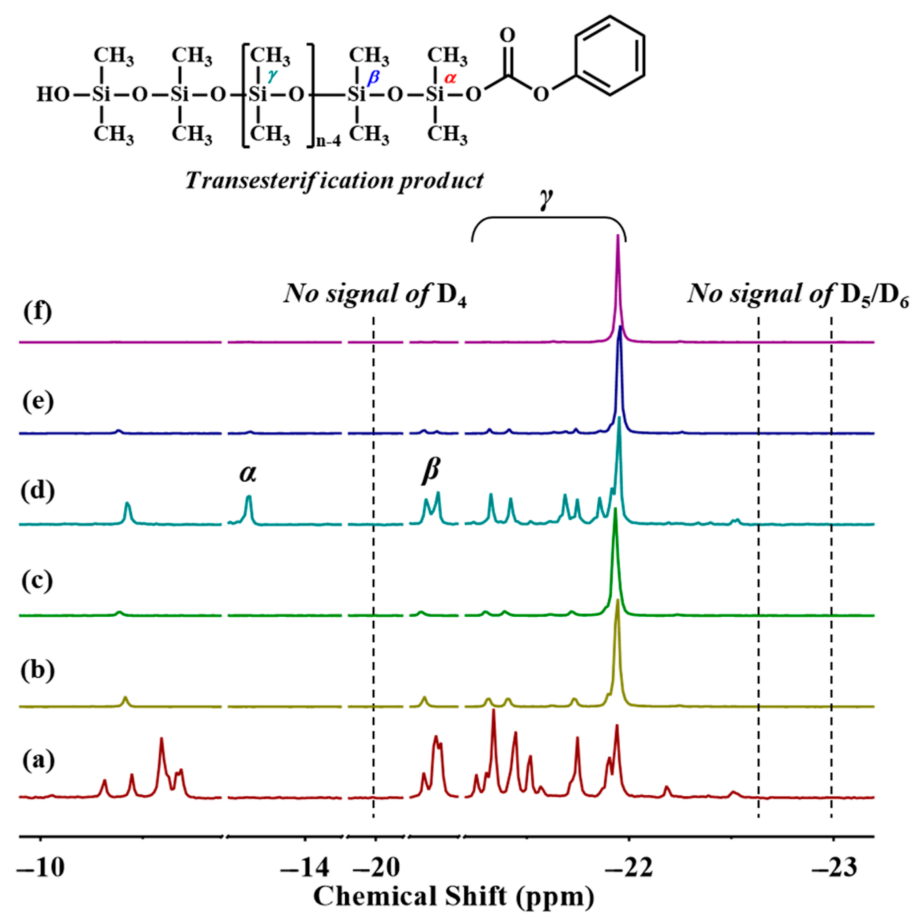

Figure 8. ${ }^{29} \mathrm{Si}_{-N M R}$ spectra of (a) Silanol $_{5.3}$, (b) Silanol $_{22.5}$, and (c) Silanol ${ }_{56.2}$, as well as the final transesterification products of (d) $\operatorname{Silanol}_{5.3}$, (e) Silanol $_{22.5}$, and (f) Silanol 56.2 reacted with DPC for $100 \mathrm{~min}$ at $180^{\circ} \mathrm{C}$. 


\subsection{Influence of Silanol Feeding on Conversion}

The study on the transesterification process between DPC and PDMS helped us select Silanol $_{5.3}$, which had a lower viscosity, higher hydroxyl content, and shorter chain length, for further transesterification with DPC and BPA. Due to the difference in reactivity between BPA and Silanol ${ }_{5.3}$, competition existed during the transesterification with DPC, so we expected that the feed amount of Silanol ${ }_{5.3}$ affected the PDMS conversion. Hence, we prepared a series of silanol-based copolycarbonates by varying the silanol feed amount.

The sequence distribution of BPA and Silanol ${ }_{5.3}$ moieties was determined by the chemical shifts at around $\delta 150.5-151.2 \mathrm{ppm}$ in the ${ }^{13} \mathrm{C}$-NMR spectrum (Figure 9). The carbonyl carbons split into three peaks corresponding to $C_{1}$ (PDMS-PDMS), $C_{2}$ (BPA-PDMS), and $C_{3}$ (BPA-BPA). The chemical shifts of the three peaks detected at $\delta 150.8,151.0$, and 151.1 ppm were assigned to the carbon atoms. The central carbon atom of BPA linked within the chain also split into three peaks $\left(C_{4}, C_{5}\right.$, and $\left.C_{6}\right)$ as a result of the copolymerization [33]. Molar ratios of the $C_{1}, C_{2}$, and $C_{3}$ sequences of Silanol ${ }_{5.3}$-based copolycarbonates can also be calculated by the integral ratio of the three different types of peaks [34].

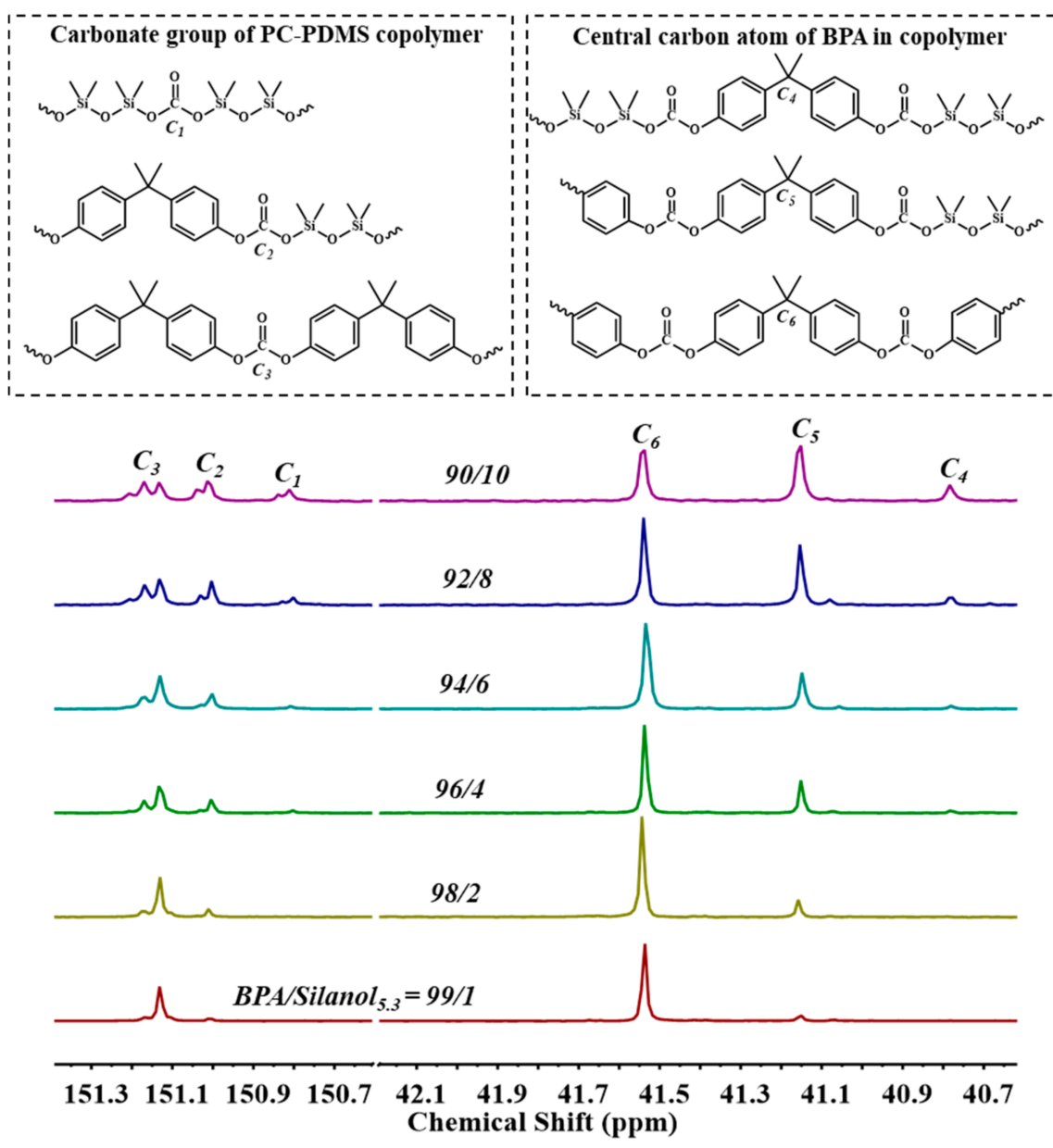

Figure 9. ${ }^{13} \mathrm{C}-\mathrm{NMR}$ spectra of PC-PDMS copolymer with different feed ratios of BPA to Silanol ${ }_{5.3}$.

Table 3 summarizes the trends of the sequence distribution of Silanol 5 -based copolycarbonates with Silanol ${ }_{5.3}$ feed amount. Table 3 shows that the contents of $C_{1}$ and $C_{2}$ structures gradually increased with increased Silanol ${ }_{5.3}$ feed amount, whereas the content of $C_{3}$ structures gradually decreased. The number-average sequence length of the BPA segment $\left(L_{n B P A}\right)$ decreased with increased $S_{i l a n o l}{ }_{5.3}$ feeding, whereas $L_{n P D M S}$ gradually increased. When the molar ratio of BPA/PDMS was $90 / 10, L_{n P D M S}$ was equal to 2, meaning that the PDMS segments in the copolymer were primarily in the form of 
Silanol $_{5.3}-\mathrm{O}-\mathrm{C}(=\mathrm{O})-\mathrm{O}-$ Silanol $_{5.3}$. Changing the feed amount of PDMS affected the distribution of PDMS segments in the copolymer.

Table 3. Microstructure of silanol-terminated PDMS copolycarbonates with different feed ratios of BPA to PDMS.

\begin{tabular}{|c|c|c|c|c|c|c|}
\hline BPA/PDMS & $C_{1}{ }^{1}(\mathrm{~mol} \%)$ & $C_{2}{ }^{1}(\mathrm{~mol} \%)$ & $C_{3}{ }^{1}(\mathrm{~mol} \%)$ & $L_{\text {nBPA }}{ }^{2}$ & $L_{\text {nPDMS }}{ }^{2}$ & $B^{3}$ \\
\hline $99 / 1$ & - & 6.5 & 93.5 & 29.9 & 1 & 1.03 \\
\hline $98 / 2$ & - & 14.3 & 85.7 & 13.0 & 1 & 1.08 \\
\hline $96 / 4$ & 4.7 & 22.4 & 72.9 & 7.5 & 1.4 & 0.84 \\
\hline $94 / 6$ & 5.0 & 25.3 & 69.6 & 6.5 & 1.4 & 0.87 \\
\hline $92 / 8$ & 12.1 & 29.0 & 58.9 & 5.1 & 1.8 & 0.74 \\
\hline $90 / 10$ & 16.7 & 33.5 & 49.7 & 4.0 & 2.0 & 0.75 \\
\hline
\end{tabular}

${ }^{1}$ Molar content of BPA-BPA, BPA-PDMS, and PDMS-PDMS sequences in the carbonyl carbon region; ${ }^{2}$ block length of BPA and PDMS measured by ${ }^{13} \mathrm{C}$-NMR (Figure S1 in Supplementary Materials); ${ }^{3}$ degrees of randomness (B) of copolymers calculated by ${ }^{13} \mathrm{C}-\mathrm{NMR}$ (Figure S1).

Table 4 demonstrates the effect of the initial feed ratio of BPA to Silanol ${ }_{5.3}$ on the molecular-structure characteristics of the Silanol ${ }_{5.3}$-based copolycarbonates. BPA and DPC were well miscible at the molecular level, but BPA was less reactive than Silanol ${ }_{5.3}$, and the poor miscibility between Silanol ${ }_{5.3}$ and DPC may need to be improved through transesterification. This phenomenon may affect the performance of the polycondensation product. For instance, the highest $M_{\eta}$ of synthesized products was achieved when the molar ratio of DPC to diols was 1:1. With decreased relative content of DPC, the conversion of Silanol ${ }_{5.3}$ was supposed to decrease. However, PDMS conversion increased when the BPA/PDMS feed ratio was $90 / 10$ probably because the short-chain, high-reactivity Silanol 5.3 fed in higher amounts was more likely to produce the $C_{1}$ structure. Consequently, conversion was higher due to the inhibition of cyclic degradation by the adjacent PC segments. The short-chain Silanol $_{5.3}$ was used as a third monomer in the copolymerization with BPA and DPC, and the PDMS conversion decreased with increased PDMS feed amount. With further increased PDMS feed amount, PDMS conversion remained over 65\%.

Table 4. Molecular-structure characteristics of silanol copolycarbonates with different feed ratios of BPA and Silanol 5.3 obtained from ${ }^{1} \mathrm{H}-\mathrm{NMR}$.

\begin{tabular}{|c|c|c|c|c|c|c|}
\hline BPA/PDMS ${ }^{1}$ & DPC/diols $^{2}$ & $M_{\eta}(\mathrm{g} / \mathrm{mol})$ & $\Delta C(\%)$ & Conversion $^{3}(\%)$ & $T_{\mathrm{g}}{ }^{4}\left({ }^{\circ} \mathrm{C}\right)$ & $T_{\mathrm{d}, 5 \%}{ }^{5}\left({ }^{\circ} \mathrm{C}\right)$ \\
\hline $100 / 0$ & 1.06 & 15,900 & 0.20 & - & 148.4 & 424 \\
\hline $99 / 1$ & 1.05 & 17,500 & 0.18 & 85.8 & 137.7 & 424 \\
\hline $98 / 2$ & 1.04 & 18,400 & 0.22 & 70.6 & 131.8 & 402 \\
\hline $96 / 4$ & 1.02 & 29,200 & 0.11 & 66.0 & 128.4 & 400 \\
\hline $94 / 6$ & 1.00 & 37,800 & 0.18 & 68.2 & 129.5 & 420 \\
\hline $92 / 8$ & 0.98 & 26,000 & 0.31 & 67.9 & 109.9 & 391 \\
\hline $90 / 10$ & 0.96 & 24,700 & 0.50 & 72.6 & 101.7 & 385 \\
\hline
\end{tabular}

${ }^{1}$ Based on the initial molar percentages of BPA and PDMS; ${ }^{2}$ based on the initial feeding ratios of DPC and diols; ${ }^{3}$ calculated by ${ }^{1} \mathrm{H}-\mathrm{NMR}$ analysis according to Equation (3); ${ }^{4}$ measured by DSC at a heating rate of $10{ }^{\circ} \mathrm{C} \mathrm{min}^{-1}$ (2nd scan); ${ }^{5}$ degradation temperature for $5 \%$ weight loss was determined by TGA at a heating rate of $10^{\circ} \mathrm{C} \mathrm{min}^{-1}$ (with $\mathrm{N}_{2}$ ).

\subsection{Influence of Chain Length on Conversion}

After the investigation of transesterification in Section 3.2, we found differences in the miscibility between DPC and PDMS with different chain lengths, which required improvement through transesterification. The equilibrium transesterification levels of PDMS with different chain lengths were dissimilar, and the residual PDMS oligomers increased the tendency of side reactions to occur in the polycondensation stage. Furthermore, PDMS conversion in the transesterification stage directly determined PDMS conversion in the final products. Therefore, we selected PDMS with different chain lengths as substrates and controlled the same feeding ratio of BPA to PDMS to investigate the effect of the average chain length of PDMS on its conversion. 
Figure 10 shows the ${ }^{13} \mathrm{C}-\mathrm{NMR}$ spectra of PC-PDMS copolymers prepared from different-chain-length silanols under the same conditions. A longer PDMS block length in copolymers caused the $B$ to approach 1 , and random copolymers were more easily obtained. Table 5 presents the molecular structure of PC-PDMS copolymers prepared from PDMS with different chain lengths. PDMS conversion significantly decreased when longer-chain PDMS was added ( $68 \%$ vs. $13 \%)$.

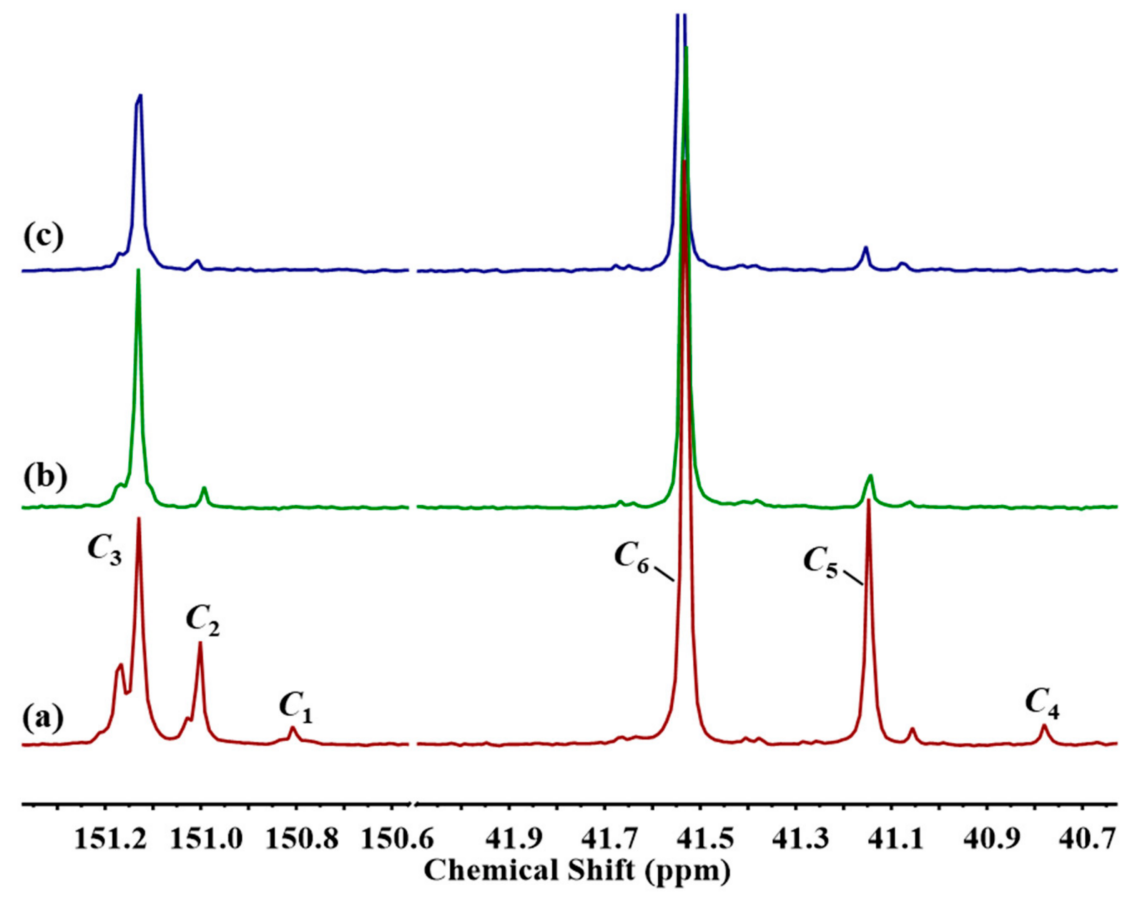

Figure 10. ${ }^{13}$ C-NMR spectra of PC-PDMS copolymers using (a) Silanol 5.3 , (b) Silanol 22.5 , and (c) Silanol $_{56.2}$ as raw materials with a feeding mole ratio of BPA/PDMS $=94 / 6$.

Table 5. Molecular-structure characteristics of PC-PDMS copolymers with different chain lengths of silanol-terminated PDMS obtained from ${ }^{1} \mathrm{H}-\mathrm{NMR}$ and ${ }^{13} \mathrm{C}-\mathrm{NMR}$.

\begin{tabular}{|c|c|c|c|c|c|c|}
\hline Material Code & BPA/PDMS ${ }^{1}$ & PDMS $^{2}\left(w t^{\%}\right)$ & Conversion $^{2}(\%)$ & $L_{\mathrm{nBPA}}{ }^{3}$ & $L_{\text {nPDMS }}{ }^{3}$ & $B^{3}$ \\
\hline Silanol $_{5.3}$ & $94 / 6$ & 6.5 & 68.2 & 6.5 & 1.4 & 0.87 \\
\hline Silanol $_{22.5}$ & $94 / 6$ & 6.9 & 67.7 & 28.2 & 1.0 & 1.04 \\
\hline Silanol$_{56.2}$ & $94 / 6$ & 1.4 & 13.1 & 50.3 & 1.0 & 1.02 \\
\hline
\end{tabular}

${ }^{1}$ Based on the initial molar percentages of BPA and PDMS; ${ }^{2}$ determined by ${ }^{1} \mathrm{H}-\mathrm{NMR}$ analysis; ${ }^{3}$ calculated by ${ }^{13} \mathrm{C}-\mathrm{NMR}$.

To improve the conversion of long-chain PDMS in the polycondensation process and to suppress side reactions such as cyclic degradation, the critical transesterification level of DPC and PDMS must be reached to achieve mutual miscibility. The equilibrium conversion rate of PDMS must also be increased to introduce as much PDMS into the PC oligomers as possible at a lower temperature. Accordingly, we proposed a countermeasure to overcome this problem of low equilibrium conversion of PDMS in the transesterification stage by increasing the amount of $\mathrm{KOH}$ used as catalyst (Table 6).

Figure 11 shows the curves of transesterification level of long-chain Silanol ${ }_{56.2}$ and DPC catalyzed by different amounts of $\mathrm{KOH}$ as a function of time. With increased $\mathrm{KOH}$ amount, the equilibrium transesterification level of long-chain Silanol ${ }_{56.2}$ increased ( $49.0 \%$ vs. $38.6 \%$ ), and this idea can be carried over to the preparation of the polycondensation products. Table 7 provides information about the molecular structure of the PC-PDMS copolymers prepared from long-chain Silanol 56.2 catalyzed by different amounts 
of $\mathrm{KOH}$. Increased equilibrium conversion at the transesterification stage significantly increased PDMS conversion throughout the polycondensation (90.4\% vs. $13.1 \%)$.

Table 6. Polymerization of silanol copolycarbonates with different chain lengths of PDMS and BPA as two different diols and DPC as the carbonate source.

\begin{tabular}{|c|c|c|c|c|c|c|}
\hline Material Code & BPA/PDMS ${ }^{1}$ & DPC/diols ${ }^{2}$ & $M_{\eta}{ }^{3}(\mathrm{~g} / \mathrm{mol})$ & $\Delta C^{4}(\%)$ & $T_{\mathrm{g}}{ }^{5}\left({ }^{\circ} \mathrm{C}\right)$ & $T_{\mathrm{d}, 5 \%}{ }^{6}\left({ }^{\circ} \mathrm{C}\right)$ \\
\hline Pure PC & $100 / 0$ & 1.06 & 15,900 & 0.20 & 148.4 & 424 \\
\hline Silanol $_{5.3}$ & $94 / 6$ & 1.00 & 37,800 & 0.18 & 129.5 & 420 \\
\hline Silanol $_{22.5}$ & $94 / 6$ & 1.00 & 25,000 & 0.09 & 139.7 & 412 \\
\hline Silanol $_{56.2}$ & $94 / 6$ & 1.00 & 37,000 & 0.23 & 150.7 & 432 \\
\hline
\end{tabular}

${ }^{1}$ Based on the initial feeding ratios of BPA and PDMS; ${ }^{2}$ based on the initial molar percentages of DPC and diols; ${ }^{3}$ measured by an Ubbelohde viscometer using $\mathrm{CHCl}_{3}$ as the solvent through Equations (4) and (5); ${ }^{4}$ determined by UV-vis spectrometer through Equation (7); ${ }^{5}$ measured by DSC at a heating rate of $10^{\circ} \mathrm{C} \mathrm{min}^{-1}$ (2nd scan); ${ }^{6}$ degradation temperature for $5 \%$ weight loss was measured by TGA at a heating rate of $10^{\circ} \mathrm{C} \mathrm{min}^{-1}$ (with $\mathrm{N}_{2}$ ).

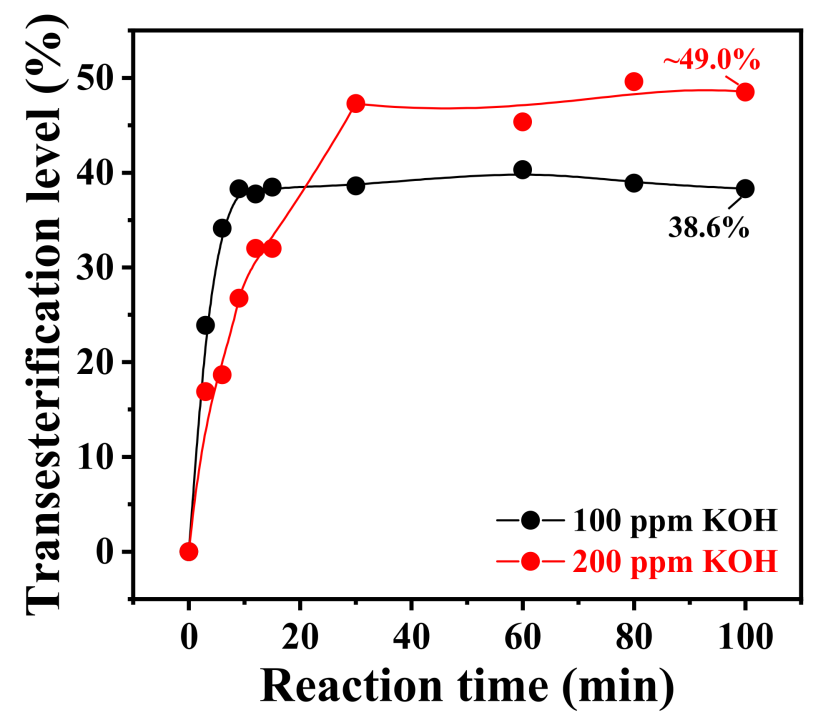

Figure 11. Time dependence of transesterification level of Silanol 56.2 reacted with DPC under the catalysis of different amounts of $\mathrm{KOH}$ at $180^{\circ} \mathrm{C}$.

Table 7. Molecular-structure characteristics of PC-PDMS copolymers prepared by different amounts of $\mathrm{KOH}$ obtained from ${ }^{1} \mathrm{H}-\mathrm{NMR}$ and ${ }^{13} \mathrm{C}-\mathrm{NMR}$.

\begin{tabular}{|c|c|c|c|c|c|c|}
\hline Material Code & BPA/PDMS ${ }^{1}$ & PDMS $^{2}(w t \%)$ & Conversion $^{2}(\%)$ & $L_{\text {nBPA }}{ }^{3}$ & $L_{\text {nPDMS }}{ }^{3}$ & $B^{3}$ \\
\hline Silanol $_{56.2}$ & $94 / 6$ & 1.4 & 13.1 & 50.3 & 1.0 & 1.02 \\
\hline Silanol $_{56.2} 4$ & $94 / 6$ & 9.3 & 90.4 & 25.2 & 1.0 & 1.04 \\
\hline
\end{tabular}

${ }^{1}$ Based on the initial molar percentages of BPA and PDMS; ${ }^{2}$ determined by ${ }^{1} \mathrm{H}-\mathrm{NMR}$ analysis; ${ }^{3}$ calculated by ${ }^{13} \mathrm{C}-\mathrm{NMR} ;{ }^{4}$ a $\mathrm{KOH}$ amount of $200 \mathrm{ppm}$ to diols on a mole basis was used.

\section{Conclusions}

We investigated the transesterification process between DPC and PDMS with different chain lengths using $\mathrm{KOH}$ as catalyst and successfully prepared a series of high-molecularweight PC-PDMS copolymers with low color difference through melt polycondensation. Transesterification experiments confirmed that with increased chain lengths of PDMS, the difficulty of miscibility between PDMS and DPC increased. Consequently, a higher critical transesterification level was needed to dissolve in DPC than PDMS with lower chain lengths. Furthermore, the conversion rate of Silanol 56.2 was only $38.6 \%$ when the transesterification with DPC reached equilibrium, and unreacted PDMS oligomers were more prone to undergo side reactions in the polycondensation stage. The feed amount of PDMS and its chain length affected the conversion of PDMS throughout melt polycondensation. The 
short-chain Silanol ${ }_{5.3}$, as the third raw material in the copolymerization with BPA and DPC, was more likely to produce a $C_{1}$ structure, and PDMS conversion decreased with increased PDMS fed. With further increased average chain length of PDMS, conversion clearly decreased. With increased $\mathrm{KOH}$ amount, the equilibrium transesterification level of Silanol $_{56.2}$ and DPC was promoted, thereby enhancing the conversion rate of long-chain Silanol $_{56.2}$ in the final product $(90.4 \%$ vs. $13.1 \%)$. These results can serve as a reference for the preparation of high-conversion and high-quality PC-PDMS copolymers through melt polycondensation.

Supplementary Materials: The following are available online at https://www.mdpi.com/article/10 .3390 / polym13162660/s1, Figure S1: Typical ${ }^{13}$ C-NMR spectrum (CDCl $\left.3,150 \mathrm{MHz}\right)$ of PC-PDMS copolymer and calculation of $L_{\mathrm{nBPA}}, L_{\mathrm{nPDMS}}$ and $B$.

Author Contributions: Writing-Original Draft Preparation, Z.Z.; Writing-Review and Editing, G.W. and Z.Z. Both authors have read and agreed to the published version of the manuscript.

Funding: This research received no external funding.

Institutional Review Board Statement: Not applicable.

Informed Consent Statement: Not applicable.

Data Availability Statement: The data presented in this study are available on request from the corresponding author.

Conflicts of Interest: The authors declare no conflict of interest.

\section{References}

1. Bryant, R.G. Encyclopedia of Polymer Science and Technology; John Wiley \& Sons: New York, NY, USA, 2006.

2. Legrand, D.G.; Bendler, J.T. Handbook of Polycarbonate Science and Technology; Marcel Dekker: New York, NY, USA, 1999.

3. Schnell, H. Chemistry and Physics of Polycarbonates; Interscience: New York, NY, USA, 1964.

4. Perret, B.; Schartel, B. The effect of different impact modifiers in halogen-free flame retarded polycarbonate blends-II. Fire behaviour. Polym. Degrad. Stab. 2009, 94, 2194-2203. [CrossRef]

5. Levchik, S.V.; Weil, E.D. Overview of recent developments in the flame retardancy of polycarbonates. Polym. Int. 2005, 54, 981-998. [CrossRef]

6. Wawrzyn, E.; Schartel, B.; Seefeldt, H.; Karrasch, A.; Jäger, C. What reacts with what in bisphenol A polycarbonate/silicon rubber/bisphenol A bis(diphenyl phosphate) during pyrolysis and fire behavior? Ind. Eng. Chem. Res. 2012, 51, 1244-1255. [CrossRef]

7. Wolf, M.P.; Salieb-Beugelaar, G.B.; Hunziker, P. PDMS with designer functionalities-Properties, modifications strategies, and applications. Prog. Polym. Sci. 2018, 83, 97-134. [CrossRef]

8. Kashiwaga, T.; Gilman, J.W.; Grand, A.F; Wilkie, C.A. Silicon-based flame retardants. In Fire Retardancy of Polymeric Materials; CRC Press: New York, NY, USA, 2000.

9. Vaughn, J.H.A. Organopolysiloxane-Polycarbonate Block Copolymers. U.S. Patent 3,189,662, 15 June 1965.

10. Vaughn, J.H.A. Organopolysiloxane Polycarbonate Block Copolymers. U.S. Patent 3,419,634, 31 December 1968.

11. Aoki, Y. Polycarbonate Resin Composition and Moled Article. U.S. Patent 9617422B2, 11 April 2017.

12. Hein, C.L.; Patil, R.; Zhou, B.; Lin, G.Y.; Schmidt, C.; Zoller, D.; Ma, S.L.; Hassman, C. Polycarbonate Copolymers, Articles Formed Therefrom, and Methods of Manufacture. W.O. Patent 2018164706A1, 13 September 2018.

13. Chun, B.K.; Bahn, H.M.; Hwang, Y.Y.; Park, J.J.; Hong, M.H.; Lee, K.J.; Ko, U.; Son, Y.W. Copolycarbonate and Composition Containing Same. W.O. Patent 2016089118A2, 9 June 2016.

14. Kimura, T.; Tando, K.; Oda, K. Polycarbonate-Polydiorganosiloxane Copolymer, Resin Composition of PolycarbonatePolydiorganosiloxane Copolymer, and Production Method for Resin Composition of Polycarbonate-Polydiorganosiloxane Copolymer. W.O. Patent 2019124556A1, 27 June 2019.

15. Pang, X.; Ge, X.; Ji, J.; Liang, W.; Liu, R.; Chen, X.; Yin, G.; Ge, J. Improving oxygen permeability and thermostability of polycarbonate via copolymerization modification with bio-phenol polysiloxane. Polymers 2019, 11, 1302. [CrossRef] [PubMed]

16. Ohashi, K.E.; Suzuki, H.; Muraoka, T.; Yoshisato, E.; Nagashima, R. Method of Separating and Recovering Aromatic Carbonate and Production Process. U.S. Patent 20030162989A1, 28 August 2003.

17. Lee, J.N.; Park, C.; Whitesides, G.M. Solvent compatibility of poly (dimethylsiloxane)-based microfluidic devices. Anal. Chem. 2003, 75, 6544-6554. [CrossRef] [PubMed]

18. Barton, A.F.M. Solubility parameters. Chem. Rev. 1975, 75, 731-753. [CrossRef]

19. King, J.A., Jr;; McCloskey, P.J.; Davis, G.C. Method for Preparation of Block Copolysiloxanecarbonate. U.S. Patent 5,504,177, 2 April 1996. 
20. Koenig, A.; Ebert, W.; Koehler, W. Process for the Preparation of Polysiloxane-Polycarbonate Block Cocondensates. D.E. Patent 19710081A1, 17 September 1998.

21. Zhang, S.M.; Zhang, H.X.; Zhang, W.Y.; Wu, Z.Q.; Chen, F.; Fu, Q. Toughening of polycarbonate through reactive melt blending: Effect of hydroxyl content and viscosity of hydroxyl-terminated polydimethysiloxane. Chin. J. Polym. Sci. 2014, 32, 823-833. [CrossRef]

22. Zhou, W.J.; Osby, J. Siloxane modification of polycarbonate for superior flow and impact toughness. Polymer 2010, 51, 1990-1999. [CrossRef]

23. Scott, D.W. Equilibria between linear and cyclic polymers in methylpolysiloxanes. J. Am. Chem. Soc. 1946, 68, 2294-2298. [CrossRef]

24. Banach, T.E.; Davis, G.C.; Smigelski, P.M.; McCloskey, P.J. Method for Making Siloxane Copolycarbonates. U.S. Patent 6252013B1, 26 June 2001.

25. Konig, A.; Kuhling, S. Process for the Production of Poly(Diorganosiloxane)/Polycarbonate Block Copolymers. U.S. Patent 5,783,651, 21 July 1998.

26. Malmgren-Hansen, B.; Olesen, S.; Pommer, K.; Funch, L.W.; Pedersen, E. Survey of Chemical Substances in Consumer Products Survey No. 32-2003 Emission and Evalution of Chemical Substances from Selected Electrical and Electronic Products; The Danish Environmental Protection Agency: Copenhagen, DA, USA, 2003.

27. Woodburm, K.; Drottar, K.; Domoradzki, J.; Durham, J.; Mcnett, D.; Jezowski, R. Determination of the dietary biomagnification of octamethylcyclotetrasiloxane and decamethylcyclopentasiloxane with the rainbow trout (Oncorhynchus mykiss). Chemosphere 2013, 93, 779-788. [CrossRef] [PubMed]

28. Yilgor, I.; Yilgor, E. Thermal stabilities of end groups in hydroxyalkyl terminated polydimethylsiloxane oligomers. Polym. Bull. 1998, 40, 525-532. [CrossRef]

29. He, M.J.; Chen, W.X.; Dong, X.X. Polymer Physics, 3rd ed.; Fundan University Press: Shanghai, China, 2007.

30. Cezard, C.; Rice, C.A.; Suhm, M.A. OH-stretching red shifts in bulky hydrogen-bonded alcohols: Jet spectroscopy and modeling. J. Phys. Chem. A 2006, 110, 9839-9848. [CrossRef] [PubMed]

31. Vallejo-Montesinos, J.; Villegas, A.; Jacobo-Azuara, A.; Martínez, J.M.; Ramírez, E.; Cervantes, J. Synthesis and Properties in Solution of Gaussian Homo Asymmetric Polysiloxanes with a Bulky Side Group. J. Inorg. Organomet. P. 2012, 22, 1332-1340. [CrossRef]

32. Demirci, A.; Yamamoto, S.; Matsui, J.; Miyashita, T.; Mitsuishi, M. Facile synthesis of cyclosiloxane-based polymers for hybrid film formation. Polym. Chem. 2015, 6, 2695-2706. [CrossRef]

33. Williams, E.A.; Cargioli, J.D.; Hobbs, S.Y. The ${ }^{13} \mathrm{C}$ and ${ }^{29} \mathrm{Si}$ nuclear magnetic resonance analysis of bisphenol A polycarbonatepolydimethylsiloxane block copolymers. Macromolecules 1977, 10, 782-785. [CrossRef]

34. Yamadera, R.; Murano, M. The determination of randomness in copolyesters by high resolution nuclear magnetic resonance. J. Polym. Sci. Part A Polym. Chem. 1967, 5, 2259-2268. [CrossRef] 